\title{
CARCINOID OF THE MINOR DUODENAL PAPILLA ASSOCIATED WITH PANCREAS DIVISUM: CASE REPORT AND REVIEW OF THE LITERATURE.
}

\author{
Jaques Waisberg, Leandro Luongo de Matos, Daniel Reis Waisberg, Honória Virginea Brom dos Santos, Sandra Moraes \\ Fernezlian, Vera Luiza Capelozzi
}

\section{INTRODUCTION}

Carcinoid tumors of Vater's ampulla are the most common among the extremely rare primary ampullary neuroendocrine tumors, accounting for less than $0.35 \%$ of all gastrointestinal carcinoids and are frequently associated with Von Recklinghausen's disease. ${ }^{1,2}$

Carcinoid tumors of Vater's ampulla are difficult to diagnose preoperatively because of their relatively small size and submucosal location. ${ }^{1-4}$ Consequently, their true nature is usually only discovered after appropriate immunocytochemical, histochemical, or ultrastructural studies. ${ }^{5,6}$

Carcinoid tumors of the minor papilla are also very rare. To the best of our knowledge, only 7 cases have been reported in the literature. ${ }^{6-12}$ That carcinoid tumors of the major duodenal papilla have been described more frequently than those of the minor papilla is probably because those of the major duodenal papilla often give rise to symptoms (for example jaundice and pain) that demand intensive examination or surgery; while those of the minor papilla are frequently asymptomatic..$^{13}$ These gastrointestinal tumors appear to be hormonally inactive, and abdominal pain is the main clinical feature. ${ }^{14}$

Pancreas divisum is the most common congenital variant of the pancreatic anatomy and occurs when the ductal systems of the ventral and dorsal pancreatic ducts fail to fuse. ${ }^{15-17}$ Because the ducts are not completely united, most of the pancreatic exocrine secretions enter the duodenum via the dorsal duct and minor papilla. Of the 7 cases of carcinoid tumors of the minor papilla reported in the literature, 4 were associated with pancreas divisum.

This report describes a case of an endocrine tumor of the carcinoid type, immunohistochemically a somatostatinoma, which was localized in the minor papilla and associated with pancreas divisum.

Department of Surgery and Pathology, Hospital do Servidor Público do Estado de São Paulo; Department of Pathology, São Paulo University Medical School - São Paulo/SP, Brazil.

Email: jaqueswaisberg@uol.com.br

\section{CASE REPORT}

A 57-year-old, white woman presented epigastralgia, steatorrhea, and an $8 \mathrm{~kg}$ weight loss, with an onset 1 year previously. Laboratory exams were normal except for the following: (i) presence of anemia (hemoglobin $7.5 \mathrm{~g} \%$ ), (ii) positive test for occult blood in the stool, and (iii) strongly positive (+++/4) test for fecal fat. Colonoscopy did not reveal abnormalities. Gastroduodenoscopy identified an elevated submucosal lesion with an integral mucous membrane, $2 \mathrm{~cm}$ in diameter, in the second part of the duodenum; the major duodenal papilla exhibited a normal aspect. Histopathologic exam of the duodenal lesion revealed nonspecific chronic duodenitis. Contrasted radiography of the small intestine revealed a filling defect in the second part of the duodenum, with preservation of the mucosal folds (Figure 1). Magnetic resonance cholangiopancreatography showed a pancreas with reduced dimensions, irregular borders, and dilation of the pancreatic dorsal duct throughout its extent, compatible with pancreas divisum and a chronic inflammatory process; the accessory pancreatic duct originated in the duodenal loop, with the distal portion juxtaposed to the main pancreatic duct (Figure 2). In the second part of the duodenum, there was a solid, very well defined nodular image from which the duct originated. This duct extended into the cephalic area of pancreas and implanted its distal portion in the main pancreatic duct. Endoscopic retrograde cholangiopancreatography revealed a submucosal lesion involving the minor duodenal papilla and for which the ostium was not observed. The major duodenal papilla exhibited a preserved aspect, and administration of contrast medium into its ostium showed a fine and short pancreatic ductal branch, corresponding anatomically to the main pancreatic duct, thereby suggesting pancreas divisum.

The patient underwent exploratory laparotomy, and duodenotomy was performed. The major duodenal papilla was identified, and presented a preserved aspect. The presence of the submucosal lesion was verified in the second part of the duodenum, being approximately $2.5 \mathrm{~cm}$ in diameter 


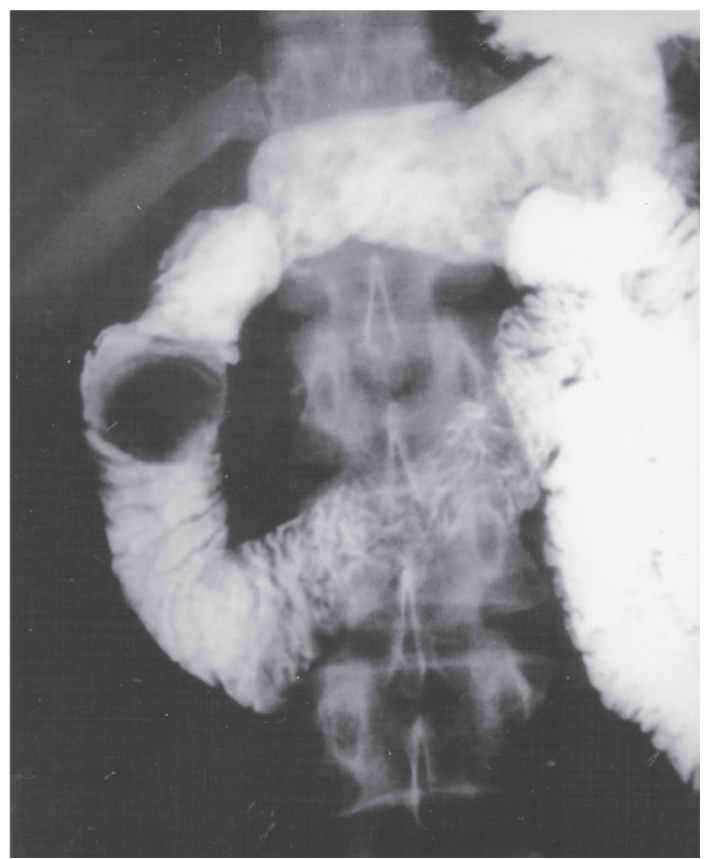

Figure 1- Contrasted radiography of the small intestine showing a defect in the radiologic filling in the second part of the duodenum. Note the welldefined and regular area with preservation of the mucosal folds.

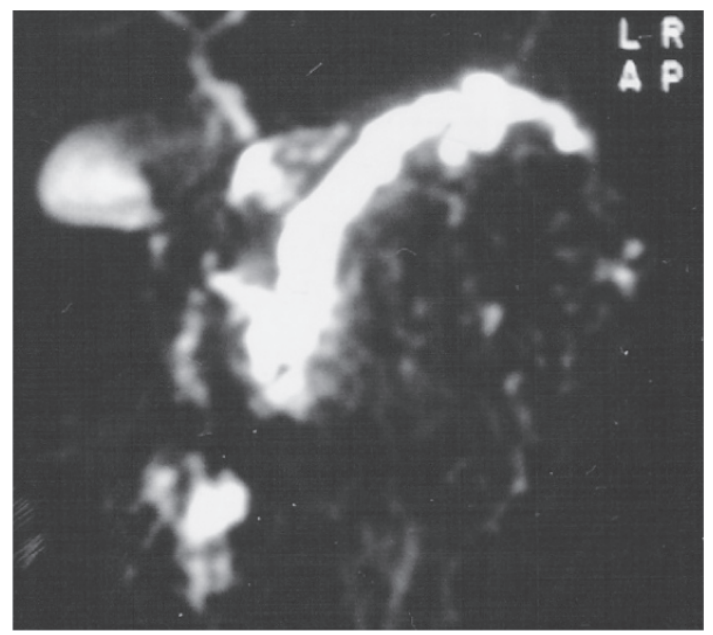

Figure 2- Magnetic resonance cholangiopancreatography with exogenous administration of secretin showing both the ventral duct and the dorsal pancreatic duct without connection between them. Santorini's duct is slightly enlarged. The pancreas presents reduced dimensions and irregular borders compatible with a chronic inflammatory process.

and having an integral mucosa (Figure 3). An orifice was identified in the apex of the duodenal lesion, which was catheterized, and contrast medium was introduced. An extensive and tortuous accessory pancreatic duct was observed (Figure 4). Frozen-section biopsy revealed a hyperplastic polyp; however, histopathologic exam in paraffin showed a carcinoid tumor of the duodenum. In a second operation, the patient underwent a partial pancreatoduodenectomy (Whipple's operation). Macroscopic examination revealed a tumor in the duodenal papilla measuring $2.7 \mathrm{~cm}$ in its largest diameter.

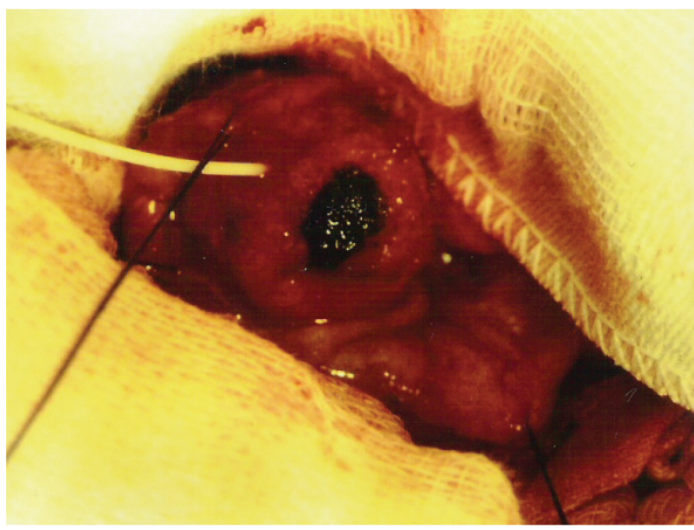

Figure 3- Aspect of the submucosal lesion in the second part of the duodenum after duodenotomy, being approximately $2.5 \mathrm{~cm}$ in diameter and having an integral mucosa. The dark area corresponds to the frozen-section biopsy site. A catheter was introduced into the orifice close to the apex of the lesion.

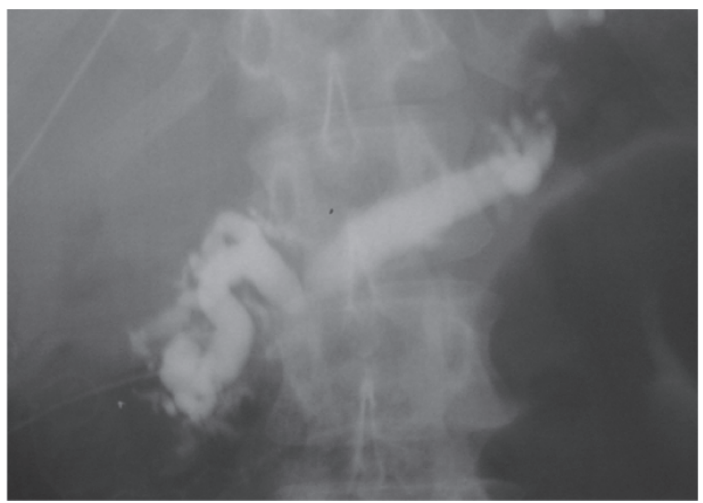

Figure 4- Pancreatic ductogram via the minor papilla cannulation. Santorini's duct was dominant and trended from the anterior part of the pancreatic head to tail.

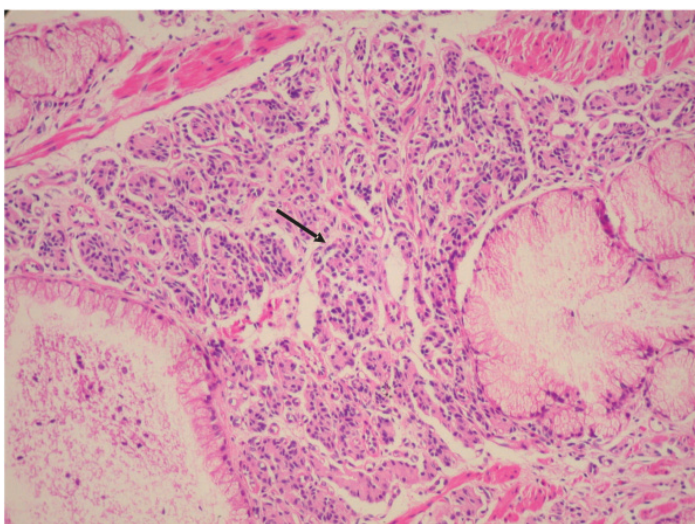

Figure 5- Photomicrograph of somatostatinoma of the minor papilla. The tumor is composed of nests of uniform cells (arrow) forming a trabecular pattern, eosinophilic granular cytoplasm, and the typical organoid arrangement of neuroendocrine cells. The nuclei are small and show fine chromatin (salt-pepper chromatin). (hematoxylin \& eosin staining; original magnification $\times 200$ ).

Histologically, the tumor was characterized as sheets and nests of small cells with regular nuclei and "salt and pepper" chromatin (Figure 5), with perineural infiltration. The immunohistochemical study was positive for the pan-endo- 


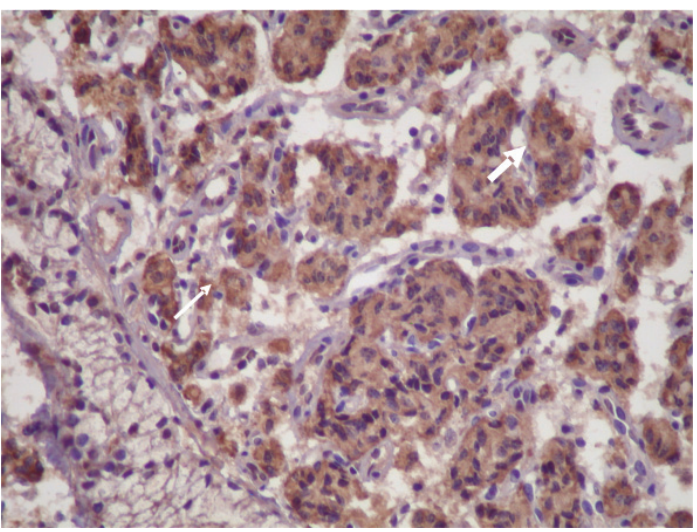

Figure 6- Somatostatin immunoreactivity in the ampullar lesion displaying uniform intense staining. Tumor cells were visible in this serotonincontaining carcinoid tumor of the minor ampulla (large arrow). Ductal epithelial cells are negative. Medium-to-large cells with pale, granular cytoplasm and round nuclei without mitotic activity can be seen (small arrow). (immunoperoxidase, $\times 400$ ).

crine markers (neuron-specific enolase, synaptophysin, and chromogranin) as well as for somatostatin (Figure 6) and negative for insulin, glucagon, serotonin, cytokeratins AE1/ AE3, and carcinoembryonic antigen. Nine lymph nodes were identified and were free from involvement by the tumor. The final diagnosis was a typical carcinoid of duodenal papilla.

The patient was recovering satisfactorily until postoperative day 21 , when she presented pulmonary thromboembolism that developed into severe respiratory insufficiency. The patient died due to severe cardiopathy with pulmonary hypertension.

\section{DISCUSSION}

On histologic examination, these neoplasms are arranged in compact nests, ribbons, trabeculae, or in a diffuse, solid pattern. Cytological examination shows neoplasms composed of a uniform population of cells with central round nuclei and granular or "salt and pepper" chromatin, rare-to-no mitotic activity, and a moderate amount of finely granular cytoplasm. ${ }^{2,14}$ Extrapancreatic somatostatinomas are characterized histologically by the presence of psammoma bodies, ${ }^{13}$ which result from the intense secretory activity of neoplastic cells, normally located in the glandular spaces. However, psammoma bodies were not observed in this case.

Immunohistochemically, tumor cells express somatostatin in $67 \%$, serotonin, cholecystokinin in $17 \%$, and insulin in $25 \%$ of cases. Glucagon and gastrin are generally not expressed by ampullary carcinoid tumors. ${ }^{5,6}$

Since carcinoids of the duodenal ampulla are rarely accompanied by endocrine symptoms, ${ }^{18-20}$ it is even more difficult to diagnose them on a clinical basis. In the case reported here, the clinical picture at presentation (epigastralgia, diarrhea, and weight loss) could be attributed to chronic pancreatitis associated with pancreas divisum and aggravated by neoplastic obstruction of the minor duodenal papilla.

Furthermore, a correct preoperative diagnosis is more difficult because biopsies are often negative, as occurred in the present case. Duodenoscopy with endoscopic retrograde cholangiopancreatography may suggest the diagnosis, but extensive and deep biopsies are often required to

Table 1- Main clinical aspects, morphologic features, treatment modalities, and outcome of cases of carcinoid of the minor duodenal papilla

\begin{tabular}{|c|c|c|c|c|c|c|c|c|c|}
\hline Author & Sex & Age & Clinical picture & $\begin{array}{l}\text { Pre-operative } \\
\text { diagnosis: } \\
\text { Pancreas } \\
\text { Divisuum }\end{array}$ & $I$ & Treatment & Size $(\mathrm{cm})$ & Metastasis & Outcome \\
\hline Malone et al ${ }^{6}$ & $\mathrm{M}$ & 46 & $\begin{array}{l}\text { Epigastric pain,weight loss, } \\
\text { anorexia, steatorrhea }\end{array}$ & Yes & No & Local resection & $0.5-0.75$ & No & $\begin{array}{l}\text { Alive, } \\
16 \text { months }\end{array}$ \\
\hline Stömmer et $\mathrm{al}^{7}$ & F & 56 & Jaundice, weight loss & No & Yes & Duodenopancreatectomy & 0.3 & No & $\begin{array}{l}\text { No } \\
\text { information }\end{array}$ \\
\hline Lowes et $\mathrm{al}^{8}$ & $\mathrm{~F}$ & 50 & $\begin{array}{l}\text { Abdominal pain, weight loss, } \\
\text { diarrhea }\end{array}$ & Yes & Yes & Duodenopancreatectomy & $1.0-2.0$ & $\begin{array}{l}\text { Lymph } \\
\text { nodes }\end{array}$ & $\begin{array}{l}\text { No } \\
\text { information }\end{array}$ \\
\hline Borobia et $\mathrm{al}^{9}$ & $\mathrm{~F}$ & 46 & $\begin{array}{l}\text { Neurofibromatosis, diarrhea, } \\
\text { steatorrhea }\end{array}$ & Yes & No & Local resection of papilla $*$ & $\begin{array}{l}\text { No } \\
\text { information }\end{array}$ & No & Alive, 3 years \\
\hline Singh et $\mathrm{al}^{10}$ & $\mathrm{~F}$ & 35 & Relapsing pancreatitis & Yes & Yes & Sphincteroplasty & 1.0 & No & Alive, 6 months \\
\hline Outtas et $\mathrm{al}^{11}$ & F & 45 & Nodular panniculitis & Yes & Yes & Duodenopancreatectomy & 0.6 & No & Alive, 1 year \\
\hline Wang et $\mathrm{al}^{12}$ & M & 50 & $\begin{array}{l}\text { Multiple melenas, } \\
\text { polycythemia vera }\end{array}$ & Yes & No & Transduodenal resection & 0.9 & No & Alive, 3 years \\
\hline $\begin{array}{l}\text { Waisberg et al } \\
\text { (present case) }\end{array}$ & $\mathrm{F}$ & 57 & $\begin{array}{l}\text { Abdominal pain, } \\
\text { diarrhea and weight loss }\end{array}$ & No & Yes & Duodenopancreatectomy & 2.7 & No & $\begin{array}{l}\text { Dead, day } 21, \\
\text { postoperative } \\
\text { complications }\end{array}$ \\
\hline
\end{tabular}

*double lesion (carcinoid of the major and minor duodenal papillae) 
confirm the histologic nature of the tumor. ${ }^{2-4}$ Positive tissue diagnosis is optimized when biopsies are taken from the edges of the papillotomy wound or snare biopsies of a protruded papilla are performed., ${ }^{2,3}$

The clinical and morphologic characteristics of the 8 patients with reported carcinoid tumors of the minor papilla are summarized in Table 1.

A review by Hatzitheoklitos et $\mathrm{al}^{20}$ shows that $46 \%$ of major duodenal ampulla carcinoids greater than $2 \mathrm{~cm}$, $50 \%$ of tumors between 1 and $2 \mathrm{~cm}$, and $66 \%$ of tumors less than $1 \mathrm{~cm}$ in diameter exhibit metastases. These data indicate that carcinoids involving the major duodenal ampulla metastasize in $50 \%$ of cases, irrespective of primary tumor size. Thus, tumor size alone cannot clinically determine the extent of the operation. ${ }^{19}$ This, in addition to the safety of pancreatoduodenectomy when performed in specialized centers, indicates that
Whipple's operation is the most appropriate treatment for ampullary carcinoids. ${ }^{19}$

However, local excision with lymph node dissection has been suggested for tumors less than $2 \mathrm{~cm}$ in diameter. ${ }^{19}$ Provided that the main pancreatic duct is not involved, this form of treatment can be expected to achieve good results in terms of being free from operative complications. On the other hand, when the pancreatic duct is involved, the operative morbidity is higher, so some advantages that might be gained from local excision are lost. In such cases and particularly with more extensive local involvement, pancreatoduodenectomy is indicated. ${ }^{20}$ The prognosis for carcinoid of the minor duodenal papilla following treatment is good, reaching a 5-year survival of $90 \%,{ }^{13}$ nevertheless, a meticulous follow-up after surgical resection is indicated since some carcinoid tumors can metastasize. ${ }^{10}$

\section{REFERENCES}

1. Makhlouf HR, Burke AP, Sobin LH. Carcinoid tumors of the ampulla of Vater. A comparison with duodenal tumors. Cancer. 1999;85:1241-9.

2. Stamm B, Hedinger CE, Saremaslani P. Duodenal and ampullary carcinoid tumors. A report of 12 cases with pathological characteristics, polypeptide content and relation to the MEN I syndrome and von Recklinghausen's disease (neurofibromatosis). Virchows Arch [Pathol Anat]. 1986;408:475-89.

3. Mulder CJJ, Festen HPM, Mertens JCC, Huibregtse K, Meuwissen SGM, Reeders JWAJ, et al. Carcinoid tumor of the ampulla of Vater presenting with biliary obstruction: report of four cases. Gastrointest Endoscopy. 1987;33:385-7.

4. Walton GF, Gibbs ER, Spencer GO, Laws HL. Carcinoid of the ampulla of Vater. Am Surgeon. 1997;63:302-4.

5. Bornstein-Quevedo L, Gamboa-Domínguez A. Carcinoid tumors of the duodenum and ampulla of Vater: a clinicomorphologic, immunohistochemical, and cell kinetic comparison. Human Pathology. 2001;32:1252-6.

6. Malone MJ, Silverman ML, Braasch JW, Jin G, Dayal Y. Early somatostatinoma of the papilla of the duct of Santorini. Arch Surg. 1985;120:1381-3.

7. Stömmer PE, Stolte M, Seifert E. Somatostatinoma of Vater's papilla and the minor papilla. Cancer. 1987;60:232-5.

8. Lowest JR, Rode J, Lees WR, Russell RCG, Cotton PB. Obstructive pancreatitis: unusual causes of chronic pancreatitis. Br J Surg. 1988;75:1129-33.

9. Borobia FG, Fabregat J, Jorba R, Poves I, Biondo S, Serrano T, et al. Exocrine pancreatic insufficiency caused by a somatostaninoma of the minor and major duodenal papilla in a patient with neurofibromatosis. Eur J Surg. 2001;167:154-6.

10. Singh VV, Bhutani MS, Draganov P. Carcinoid of the minor papilla in incomplete pancreas divisum presenting as acute relapsing pancreatitis. Pancreas. 2003;27:96-7.
11. Outtas O, Barthet M, De Troyer J, Freanck F, Garcia S. Panniculitis nodulaire et tumeur carcinoïde intracanalaire d'um pancreas divisum. Ann Dermatol Venereol. 2004;131:466-9.

12.Wang H-Y, Chen M-J, Yang T-L, Chang M-C, Chan Y-J. Carcinoid tumor of the duodenum and accessory papilla associated with polycythemia vera. World J Gastroenterol. 2005;11:3794-6.

13. Noda Y, Watanabe H, Iwafuchi M, Furuta K, Ishinara N, Satoh M, et al. Carcinoids and endocrine cell micronests of the minor and major papillae. Cancer. 1992;70:1825-33.

14. Marcial MA, Pinkus GS, Skarin A, Hinrichs HR, Warhol MJ. Ampullary somatostatinoma: psammomatous variant of gastrointestinal carcinoid tumor - an immunohistochemical and ultrastructural study. Report of a case and review of the literature. Am J Clin Pathol. 1983;80:755-61.

15. Manfredi R, Costamagna G, Brizi MG, Spina S, Maresca G, Vecchioli A, et al. Pancreas divisum and "santorinicele": diagnosis with dynamic MR cholangiopancreatography with secretin stimulation. Radiology. 2000;217:403-8.

16. Seyama Y, Kubota K, Keijii S, Endo D, Otani T, Takayama T, et al. Intraoperative direct pancreatography using ultrasound-guided puncture for accessory duct sphincteroplasty in a patient with pancreas divisum. Pancreas. 2003;27:98-100.

17. Lu, WF. ERCP and CT diagnosis of pancreas divisum and its relation to etiology of chronic pancreatitis. World J Gastroenterol. 1998;4:150-2.

18. Machado MCC, Bachella T, Jukemura J, Cunha JEM, Zerbini MCN, Machado MAC, et al. Tumor carcinóide da papila duodenal. Rev Hosp Clin Fac Med S Paulo. 1991:46:87-90.

19. Ricci J. Carcinoid of the ampulla of Vater. Local resection or pancreaticoduodenectomy. Cancer. 1993;71:686-90.

20. Hatzitheoklitos E, Büchler MW, Friess H, Poch B, Ebert M, Mohr W, et al. Carcinoid of the ampulla of Vater. Cancer. 1994;73:1580-8. 